\title{
Verification of Molecular and Conventional Techniques used in The Diagnosis of Equine Herpes Virus in Some Egyptian Governorates
}

\author{
*Morcos Ibrahim Yanni; Ebtsam, A. Abouelyazeed; Hala Abdelrehim Ali and Nadia Maher \\ Hanna
}

Virology Department, Animal Health Research Institute, Dokki, Agriculture Research Centre (ARC), Egypt.

"Corresponding Author, Morcos Ibrahim Yanni, E-mail: morcosyanni70@gmail.com

\begin{abstract}
Equid herpesviruses (EHVs) affect equine health and can cause significant economic losses to the equine industry worldwide. In the current study, the circulation of two infectious equid herpesviruses (EHV-1 and EHV-4) among different horse populations in some farms was monitored. In the present study, 50 samples of nasal secretions and tissue homogenates from neurological disease cases, abortion, neonatal foal deaths, and 36 serum samples. Samples of swabs and organs inoculated in embryonated chiken egg and Madin darby bovine kidney cell line. 29samples were positive in egg injection but no detected CPE in cell line for three passages. DNA was extracted and subjected to conventional PCR to detect the two herpesviruses' presence using specific primers. Three isolates of EHV-1 and four were detected. One EHV-1 and two EHV-4 were subjected to phylogenetic analysis. Phylogenetic analysis confirmed the existence of the isolated EHV-1 and EHV-4. They were more closely related to other previously isolated EHV-1 and EHV-4 from Egypt and other countries. Antibodies against EHV-1 and EHV-4 were tested using ELISA. The results showed that EHV-1 and EHV-4 are endemic and can be a continuous threat for horses in the absence of vaccination programs and frequent virus reactivation.
\end{abstract}

Original Article:

DOI:https://dx.doi.org/10.21608/javs .2021 .140052

Received: 07 October, 2020.

Accepted : 27 December, 2020.

Published in January, 2021.

This is an open access article under the term of the Creative Commons Attribution 4.0 (CCBY) International License . To view a copy of this license, visit: http://creativecommons.org/licenses/by/4.0/

\section{INTRODUCTION}

Horses are constantly exposed to the world's widespread equid herpesviruses (EHVs) in horse populations. The viruses belong to the Alphaherpesvirinae subfamily [six viruses: equid herpesviruses type 1 (EHV-1), EHV-3, EHV-4, EHV6, EHV-8, and EHV-9] or the Gammaherpesvirinae subfamily [three viruses; EHV-2, EHV-5, and EHV-7 (Davison et al., 2009). Horses are the natural host to EHV-1, EHV-2, EHV-3, EHV-4, and EHV-5, while donkeys are the primary host of EHV-6, EHV-7 (AsHV-2), and EHV-8 (AsHV-3). EHV-9 (Abdelgawad et al., 2016). In Egypt, monitoring is sporadic but EHV-1 or EHV-4 has been reported to circulate in the horse population (Walid Azab et al., 2019). EHV-1 and its close relative, EHV-4, cause significant economic losses to the equine industry due to clinical illnesses associated with lost time for training and performance (Patel and Heldens 2005).
Although both viruses cause respiratory disease, the only infection with EHV-1 may result in abortion, perinatal mortality and neurological disorders with clinical signs that vary in severity but can result in complete paralysis (Patel and Heldens 2005). The infection of horses with either of the two viruses is clinically and serologically difficult to distinguish because of their high genetic and antigenic similarity (Pusterla 2005). The viruses' source(s) could be from apparently healthy and/or nonhealthy in-contact carriers. These carriers could have transmitted the viruses to the horses during transportation, training periods, race competitions, or breeding (Ma et al., 2013 and Sarani et al., 2013). It is also possible that the horse keepers, jockeys, or animal health workers transmitted the viruses from infected horses to the horses by direct contact during grooming, riding, or medical examinations /treatment (Ma et al., 2013). 
Active and / or latent infection by EHV-1 and EHV-4 occurs among the equine population. These horses harbor the viruses and serve as their disseminators following the stress and reactivation of latent infections. EHV-4 infection seems to be more prevalent than EHV-1 infection among the equine population (Taghi et al., 2015). In Egypt, the virus was isolated from the aborted fetus on the chorioallantoic membrane of embryonated chicken eggs as a first record by (Hassanain et al., 2002). Other succeeding ones followed this trial by some authors, who isolated and identified the local EHV-1 strain from aborted Arabian mares and internal organ of their foeti from a private stud with a history of recurrent abortion during 2005 and 2006 (Warda et al., 2013).

The circulation of four infectious equid herpesviruses (EHV-1, EHV-2, EHV-4, and EHV-5) among different Arabian horse populations and donkeys in Egypt were monitored through measuring antibody titers against EHV-1 and EHV-4 using virus neutralization test and type-specific ELISA; the result revealed that EHV-1, EHV-2, EHV-4, and EHV-5 are endemic and can be a continuous threat for horses in the absence of vaccination programs and frequent virus reactivation (Walid Azab et al., .2019). Standard diagnostic methods for EHV-1 and related viruses are wellestablished, including virus isolation and serological assays, particularly virus neutralization tests (VNT) and type-specific ELISA assays (OIE, 2018). Quantitative PCR (qPCR) methods offer alternatives to virus isolation and have been proven sensitive and time-effective (Pusterla et al., 2005).

The current study's objective was to determine the prevalence of infection with EHV1 and EHV4 among horses and donkeys in Egypt and molecular comparison between the local isolate of each of them and the previously sequenced Egyptian and universal strains.

\section{MATERIALS AND METHODS}

1.CLC's Enzyme-linked immunosorbent assay (ELISA) :

Using the ELISA kit(Ingezim rinoneumonitis 14.HEV.K1 lot A69377 Ref103100-02) . Samples of 36 equine sera were tested by ELISA for the detection of EHV-1 and EHV-4 specific antibodies as described by the manufacturer. Thirty-six Serum samples taken from symptomatic cases were investigated for the presence of EHV-1 and EHV-4 specific antibodies.

\section{Virus isolation}

\subsection{On tissue culture}

Fifty clinical samples, which had been stored at $-70{ }^{\circ} \mathrm{C}$, included nasal secretions and tissue homogenates from cases of neurological disease, abortion, and neonatal foal deaths. The samples were collected from different horse farms. They were prepared and injected in 50 tissue culture flask $(25 \mathrm{ml}$.) containing MDBK confluent sheet and Leighton, flying tube-cover slip- having MDBK for one hour then suspended in RBMI maintenance media containing antibiotics. The flasks were incubated at $37{ }^{\circ} \mathrm{C}$ in a humidified 5\% $\mathrm{CO} 2$ atmosphere for seven days and checked every day for the presence of a viral cytopathic effect (CPE). The coverslips were collected after 24 hours for use in the fluorescent antibody technique. The cultures were passaged at weekly intervals for a total of three passages. In the absence of any specific CPE, the cell cultures were recorded as negative. (Stasiak et al., (2018)).

\subsection{On embryonated chicken eggs (ECE)}

The prepared laboratory samples were inoculated in ECE 9-11 days through the chorioallantoic route. The inoculated eggs were examined daily until nine days for monitoring pock lesion.

\section{Fluorescent antibody technique}

Fluorescent antibody technique was applied on frozen chorioallantoic membrane showing pock lesion for identification of the isolated virus using EHV-1antiserum manufactured from animal and plant health inspection service .national veterinary services laboratories. Ames, IA 50010 lot\#340EDV1001

\section{Molecular studies}

\subsection{Nucleic acid extraction EH1, EH4}

Whole nucleic acid extraction from selected seven positive isolated samples was performed using the QIAamp mini elute virus spin kit (Qiagen, Germany, GmbH). Briefly, 200 $\mu 1$ of the sample suspension was incubated with $25 \mu \mathrm{l}$ of Qiagen protease and $200 \mu \mathrm{l}$ of A.L. lysis buffer at $56^{\circ} \mathrm{C}$ for $15 \mathrm{~min}$. After incubation, 250 $\mu \mathrm{l}$ of $100 \%$ ethanol was added to the lysate. The sample was then washed and centrifuged following the manufacturer's recommendations. Nucleic acid was eluted with $50 \mu \mathrm{l}$ of elution buffer.

\subsection{Oligonucleotide Primers}

Supplied from (Metabion Germany) are listed in table (1). 


\section{Morcos Ibrahim Yanni et al.....}

Table 1: Primers sequences, target genes, Table 2: Table illustrating the results of different tests amplicon sizes performed on samples used at this study

\begin{tabular}{|c|c|c|c|c|}
\hline 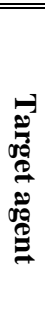 & 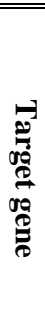 & $\begin{array}{c}\text { Primer sequence } \\
\left(5^{\prime}-3^{\prime}\right)\end{array}$ & 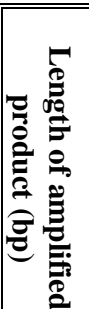 & 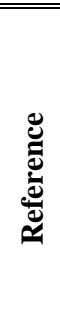 \\
\hline \multirow{2}{*}{ 要 } & \multirow{4}{*}{ 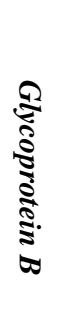 } & $\begin{array}{l}\text { F/GCAAACAACAGAGGGTCGATAGAA } \\
\text { G }\end{array}$ & \multirow{2}{*}{$\begin{array}{l}\underset{N}{\mathbb{N}} \\
\stackrel{\Xi}{\sigma}\end{array}$} & \multirow{2}{*}{ 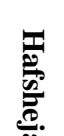 } \\
\hline & & R/GTCGATGTCGTAAAACCTGAGAG & & \\
\hline \multirow[b]{2}{*}{$\frac{T}{E}$} & & F/TATTGTTTCCGCCACTCTTGACG & \multirow{2}{*}{$\begin{array}{l}\mathscr{y} \\
\stackrel{\infty}{\sigma}\end{array}$} & 0 \\
\hline & & R/GTAGAATCGGAGGGCGTGAAGC & & 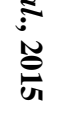 \\
\hline
\end{tabular}

\begin{tabular}{|c|c|c|c|c|c|}
\hline 参 & Nasal & tiss & hom & nates & 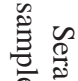 \\
\hline & Isol & & & ular & \\
\hline 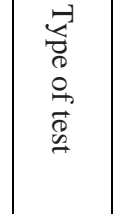 & 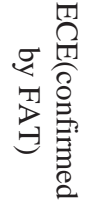 & $\hat{\Omega}$ & $\widetilde{\Omega}$ & 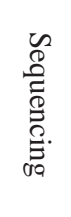 & $\underset{D}{\frac{\pi}{2}}$ \\
\hline$+\mathrm{ve}$ & 29 & 0 & 7 & 3 & 30 \\
\hline _ve & 21 & 0 & 0 & 0 & 6 \\
\hline 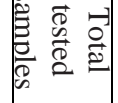 & 50 & 50 & 7 & 3 & 36 \\
\hline
\end{tabular}

\section{RESULTS}

\subsection{PCR amplification}

The Primers of EH1, EH4 PCR were utilized in a $25 \mu 1$ reaction containing $12.5 \mu 1$ of EmeraldAmp Max PCR Master Mix (Takara, Japan), $1 \mu 1$ of each primer of 20 pmol concentration, $4.5 \mu \mathrm{l}$ of water, and $6 \mu \mathrm{l}$ of DNA template. The reaction was performed in an Applied biosystem 2720 thermal cycler. The primary denaturation step was done at $95^{\circ}$.C. for $5 \mathrm{~min}$, followed by 35 cycles of $94^{\circ} \mathrm{C}$ for $30 \mathrm{sec}$, $55^{\circ} \mathrm{C}$ for $40 \mathrm{sec}$. and $72^{\circ} \mathrm{C}$ for $40 \mathrm{sec}$. A final extension step was done at $72^{\circ} \mathrm{C}$ for $10 \mathrm{~min}$.

\subsection{Analysis of the PCR Products}

The PCR products were separated by electrophoresis on 1.5\% agarose gel (Applichem, Germany, GmbH) in 1x TBE buffer at room temperature using gradients of $5 \mathrm{~V} / \mathrm{cm}$. For gel analysis, $15 \mu \mathrm{l}$ of the products were loaded in each gel slot. A gel pilot 100 bp DNA ladder (Qiagen, Germany, $\mathrm{GmbH}$ ) was used to determine the fragment sizes. The gel was photographed by a gel documentation system (Alpha Innotech, Biometra) and the data was analyzed through computer software.

\subsection{Nucleotide sequencing}

The sequencing of products of 3positive samples (1EHV-1 and2 EHV-4) was done by genetic analyzer 3500(life technology)using a big dye terminator V3.1sequencing kit. Bioedit and main workbench six software do an analysis.

\section{1- Isolation}

Twenty-nine out of 5o samples show pock lesion on the CAM of ECE from the $1^{\text {st }}$ passage. MDBK cell line fails to show any CPE for three passages

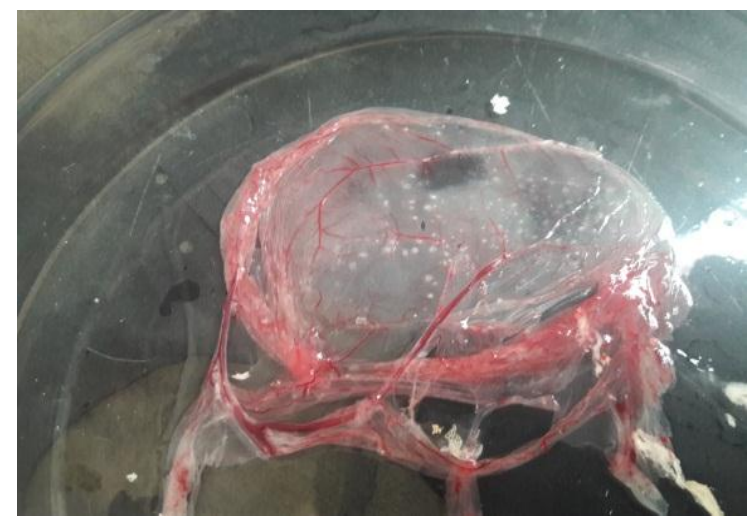

Fig.1: Pock lesions at the CAM of inoculated ECE

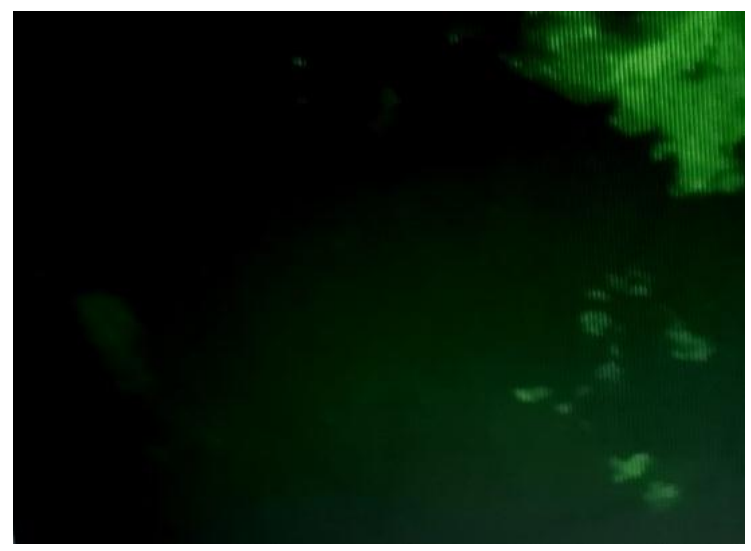

Fig.2: Indirect fluorescent antibody technique 


\section{Enzyme-linked immunosorbent assay (ELISA)}

Thirty out of 36 examined serum samples were positive for the presence of EHV-1and EHV-4 when tested with ELISA. Samples with $\mathrm{S} / \mathrm{P}$ ratio $\geq 0.3$ were considered positive.

\section{PCR results}

Table 3: The result of 7 tested samples by PCR:

\begin{tabular}{|c|c|c|}
\hline Sample & EH1 Result & EH4 Result \\
\hline 1 & - & + \\
\hline 2 & + & - \\
\hline 3 & - & + \\
\hline 4 & + & - \\
\hline 5 & - & + \\
\hline 6 & + & - \\
\hline 7 & - & + \\
\hline
\end{tabular}

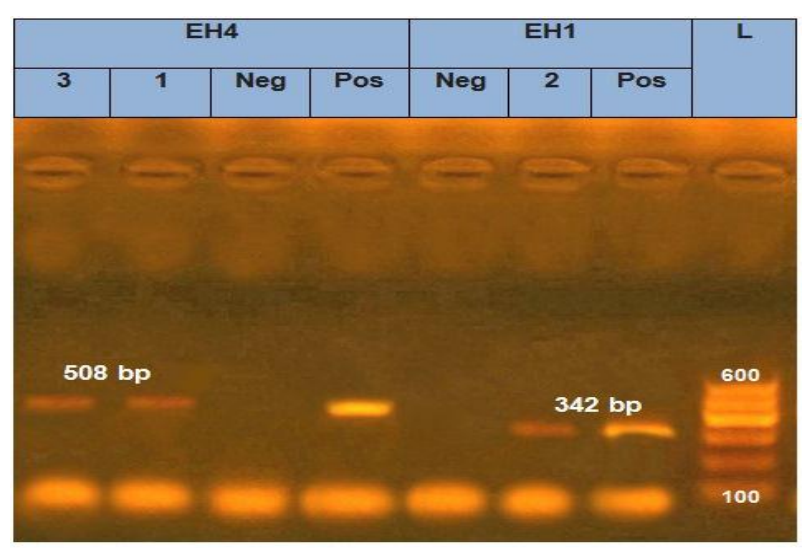

Fig.3: Showing PCR results on agarose gel

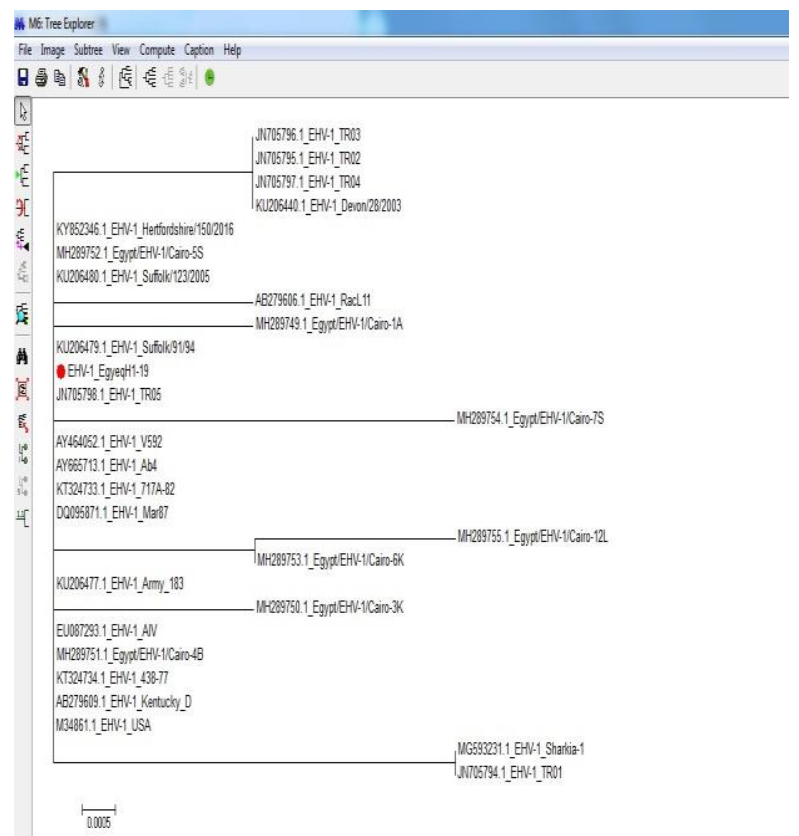

Fig.4: Phylogenetic tree of the sequenced Equine herpes1 sample isolated from a horse in 2019.

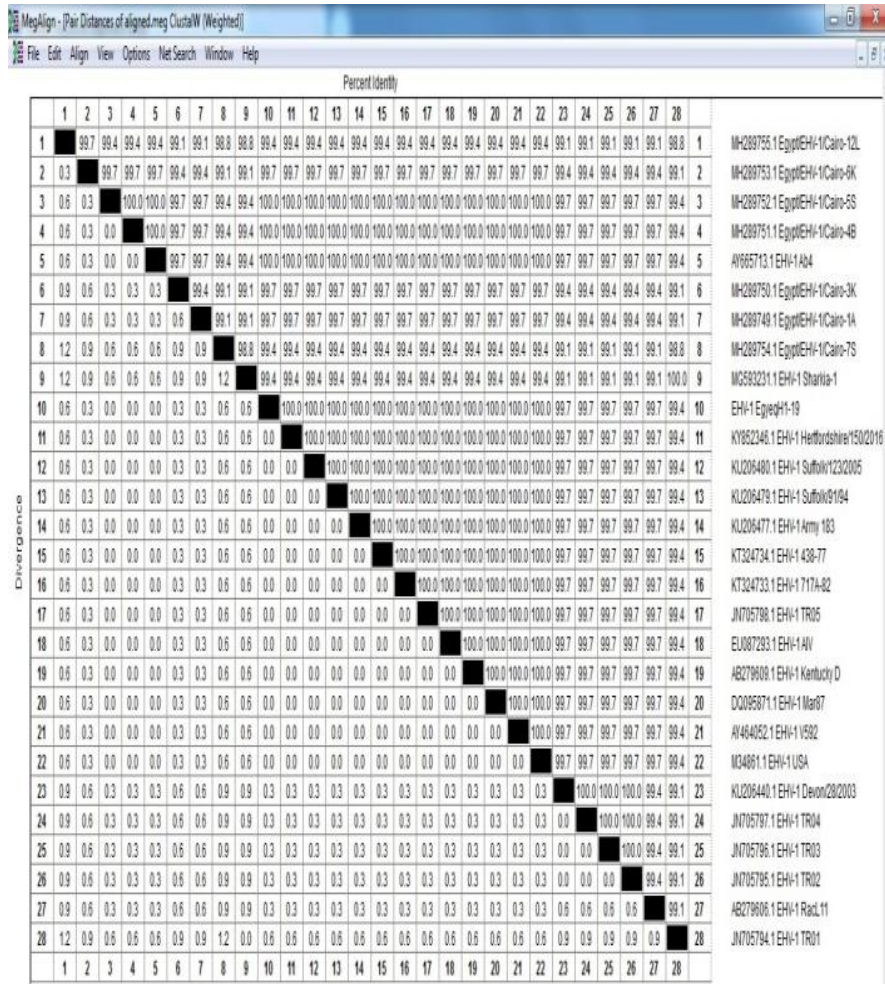

Fig.5: Sequence distance of the sequenced equine herpes 1 samples in comparison with Egyptian isolates and universal isolates.

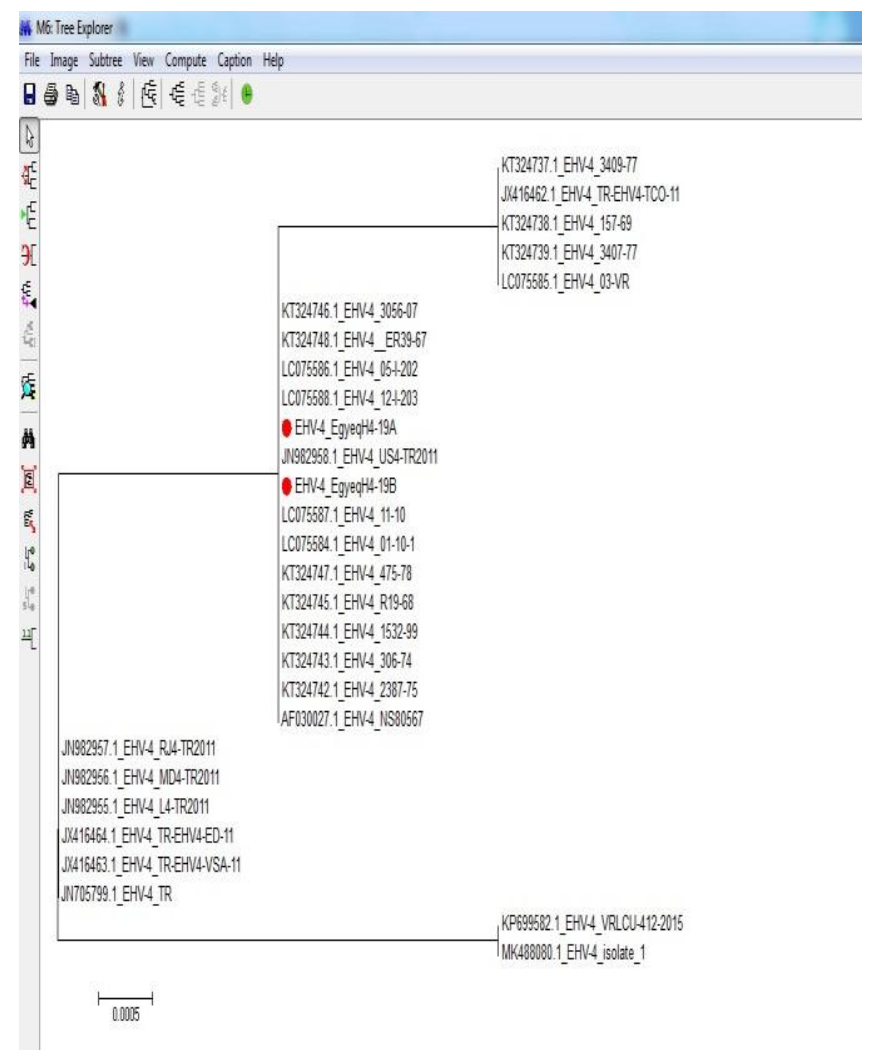

Fig.6: Phylogenetic tree of 2 sequenced Equine herpes 4 samples isolated from 2 horse in 2019 


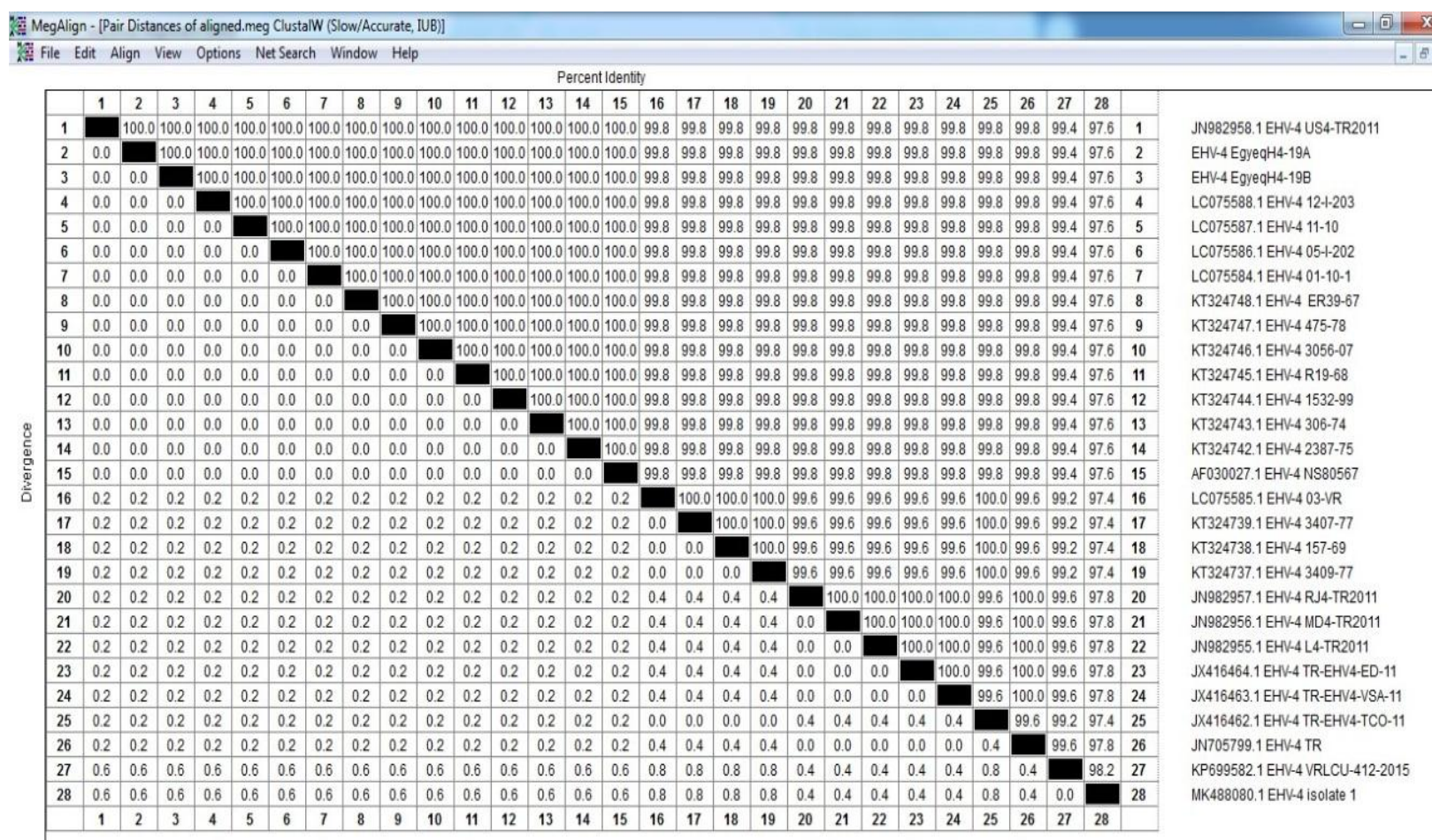

Fig.7: Sequence distance of the 2 sequenced equine herpes4 samples in comparison with Egyptian isolates and universal isolates

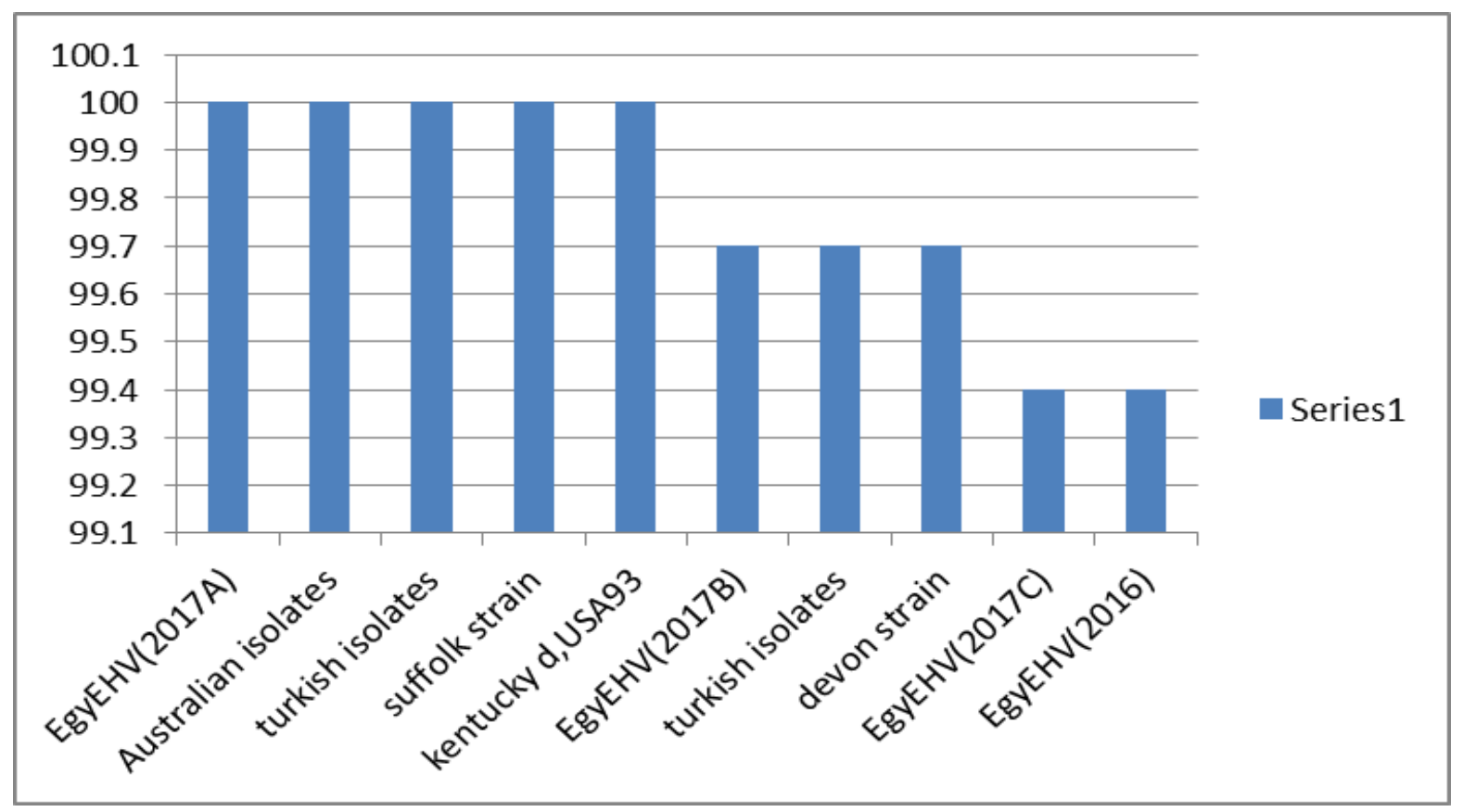

Fig 8: Chart illustrating the percentage of identity between the recently sequenced Egyptian EHV1 isolates in 2019 and the previously sequenced Egyptian and universal strains. 


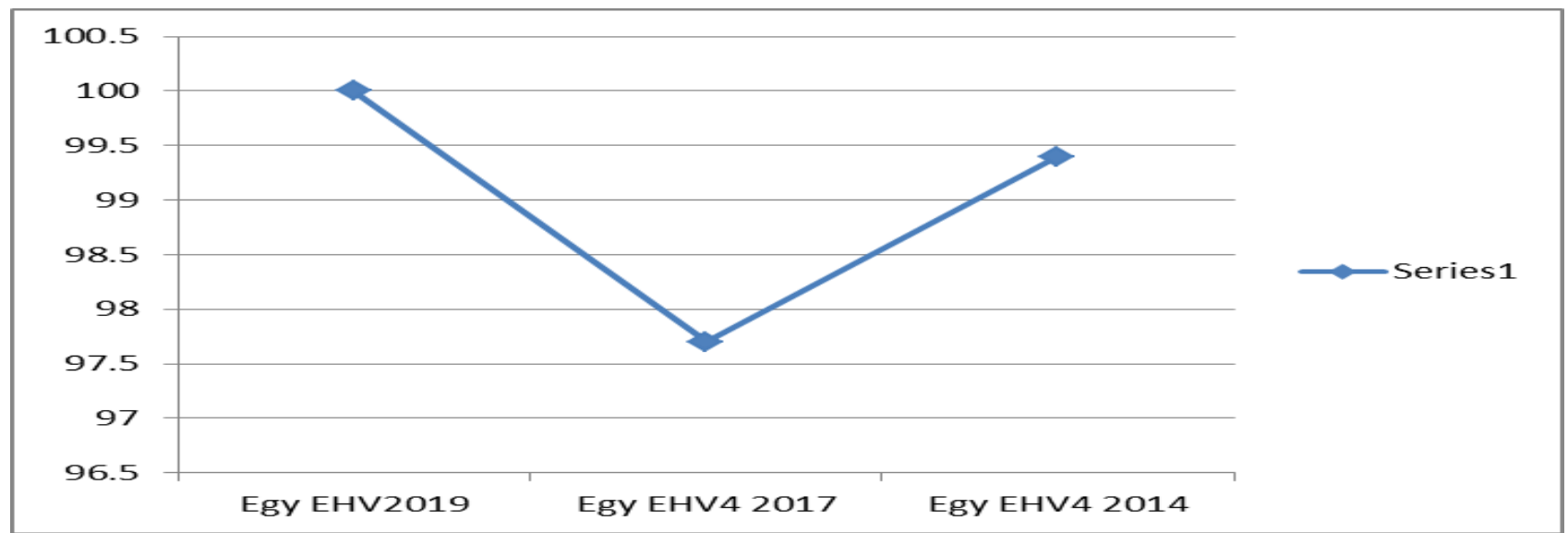

Fig. 9: Chart illustrating the percentage of identity between the recently sequenced Egyptian EHV1 isolate in 2019 and the previously sequenced Egyptian strains.

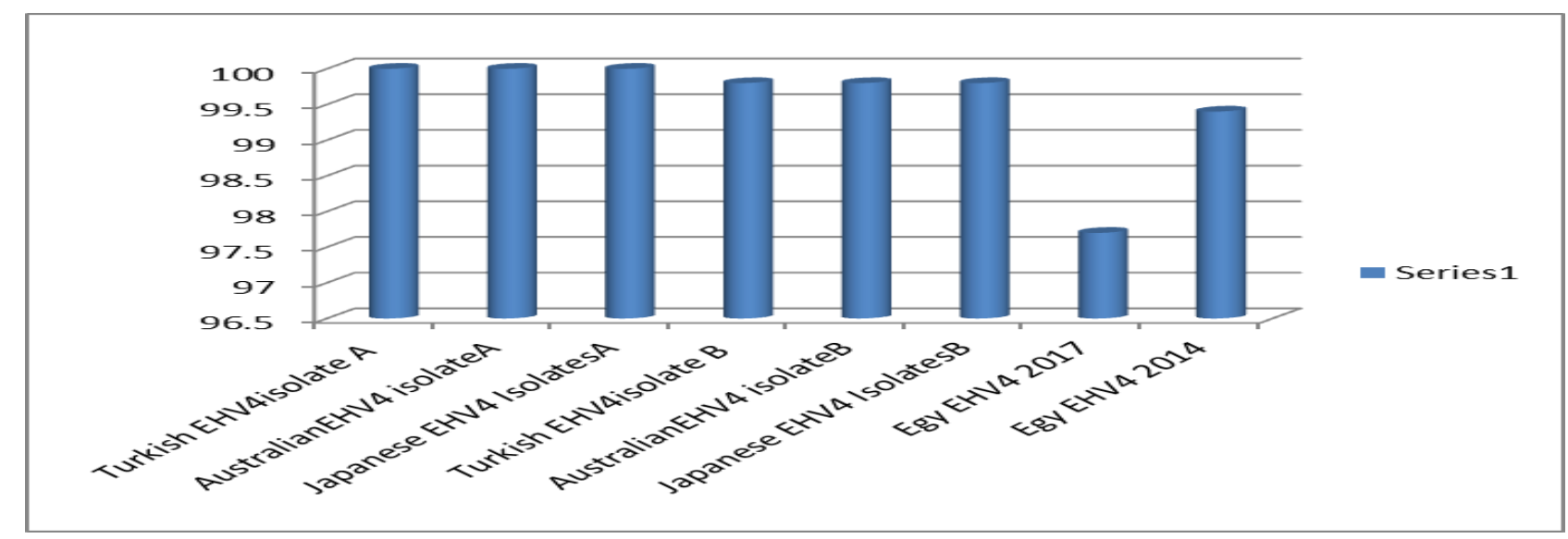

Fig.10: Chart illustrating the percentage of identity between the recently sequenced Egyptian EHV4 isolates in 2019 and the previously sequenced Egyptian and universal strains.

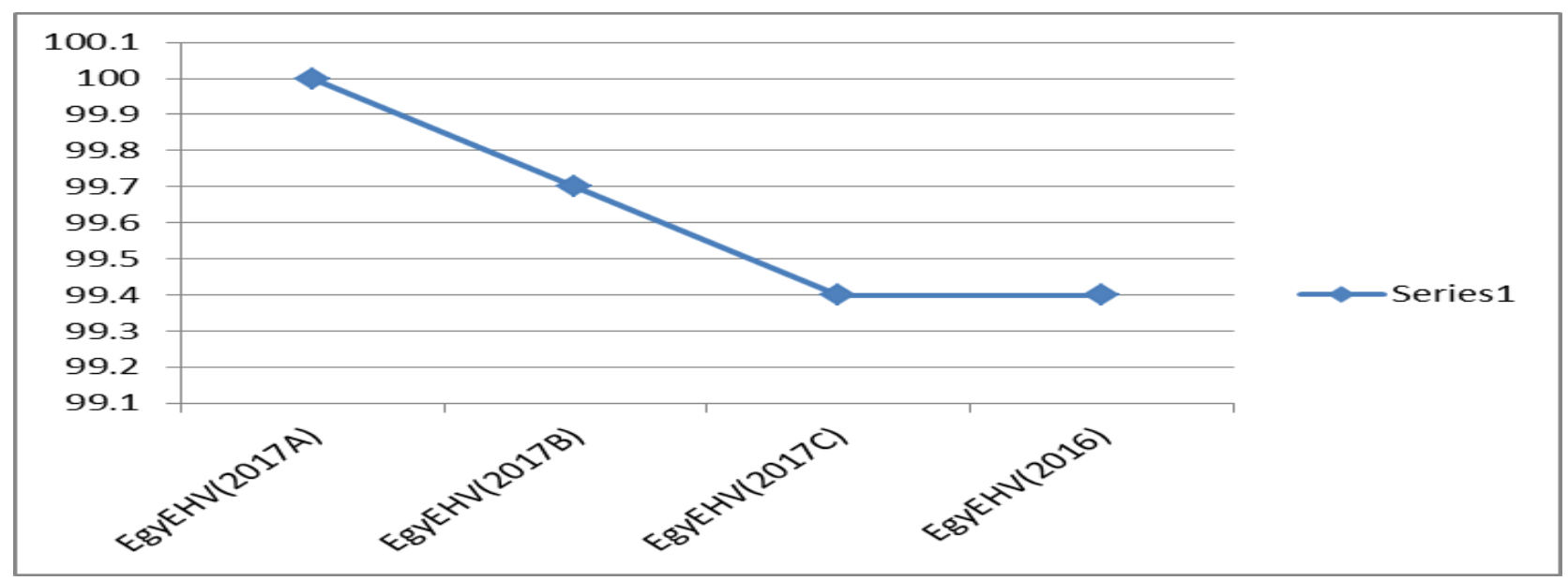

Fig.11: Chart illustrating the percentage of identity in between the recently sequenced Egyptian EHV4 isolates in 2019 and the previously sequenced Egyptian strains. 


\section{DISCUSSION}

Equine herpesviruses (EHVs) are widespread in equine populations worldwide. While the infection with equine $\alpha$-herpesviruses (EHV-1 and EHV-4) has been linked to several clinical outcomes. Equine herpesvirus 1 (EHV-1) causes respiratory disease, abortion, neonatal death, and neurological disease in equines and is endemic in most countries. Coinfections with these viruses were detected in both clinically infected and healthy horses and donkeys. This dual infection was reported before in horses and wild equids (Amer et al., 2011; Back et al., 2015; Abdelgawad et al., 2016). Furthermore, donkeys in Egypt are always stressed due to the assigned hard work, which might increase the probability of EHV shedding after reactivation ( Walid Azab et al., 2019).

The Egyptian EHV1 isolate in 2019 was closely related to previously isolated Egyptian and universal isolates. The same results were found in the sequenced EHV4 Egyptian isolates. This data accords with the worldwide spread of equine herpesviruses (Marie Garvey et al., 2019). In this study, screening of horses acutely infected by EHV-1 and EHV-4 was investigated by isolating the causative viruses, PCR, and detection of viral antibody against $\mathrm{BVH}-1$ and BVH-4.

Twenty-nine out of 50 samples show pock lesion on the CAM of ECE from the 1st passage. PCR investigated samples that show pock lesion on CAM for confirmation of the virus. EHV-1 was simultaneously detected in 3 samples while EHV-4 was detected in 4 samples. Two of the EHV-4 isolates and one EHV-1 were subjected to phylogenetic analysis. Sequencing was performed to confirm virus isolation and compare sequences retrieved directly from EHV isolated on pock lesions. Our sequences clustered together with other herpesviruses isolated worldwide.

Our isolated strain of equine herpes1 (EHV-1) has $100 \%$ identity to \{The previously isolated Egyptian equine herpes1 in 2017A (MH289752.1 and MH289751.1); the Turkish strain JN705798.1(TR05); the Australian isolates (KT324734.1 and kt324733.1) and to the following universal strain KU206480(Suffolk/123/2005), $\quad$ KU206479.1 (Suffolk/91/94, DQ095871.1(mar87), ku206477.1 (Army_183), EU087293.1 berlin2008, AB279609.1 (Kentucky, D) and M34861.1(USA93))

Our isolated strain of equine herpes1 has 99.7\% identity similar to \{the previously isolated Egyptian equine herpes1 in 2017B (MH289753.1, MH289750. 1 and MH289749.1); the Turkish strain (JN705796.1, JN705795.1, and JN705797) and to the following universal strains KU206440.1 (devon/28/2003)\}. Our isolated strain of equine herpes 1 has $99.4 \%$ identity the previously isolated Egyptian equine herpes1 in 2017C (MH289755.1 and MH289754.1) and that isolated in 2016 (MG593231.1)\}.

Our two isolated strain of equine herpes 4 are completely identical and has $100 \%$ identity with the Turkish strain(A) JN982958.1; to the Australian isolates(A) KT324748.1 ; KT324747.1; KT324746.1; KT324745.1; KT324744.1 ; KT324743.1; KT324742.1 and to the Japanese isolates(A) LC075588.1; LC075587.1; LC075586.1; LC075584.1. The analysis illustrate that our newly isolated strain were closely related to Australian isolates(B) KT324739.1; KT324738.1; KT324737.1 and to japanese strains(B) LC075585.1, and to Turkish isolates(B) (JN982957.1 JN982956.1;JN982955.1; JX416464.1;JX416463.1; JX416462.1;JN705799.1) with a percentage of $99.8 \%$. They were found to be similar to other previously isolated Egyptian equine herpes4 (isolated in 2017) with \% of identity range from $99.4 \%$ as KP699582.1 in 2014 to $97.7 \%$ as $\mathrm{Mk} 488080.1$ in 2017.

In this study, we also examined the presence of specific antibodies against equine herpesvirus type 1 (EHV-1), and equine herpesvirus type 4 (EHV-4) in equine by ELISA for EHV-1 and EHV-4 specific antibodies. The level of antibodies to herpes virus from the examined symptomatic cases is an unprotective level.

\section{CONCLUSION}

It can be concluded that The present data indicate that virus isolation in conjunction with PCR assay would lead to a higher virus identification rate in multiple respiratory infections caused by EHV-1 and EHV-4 and subsequent phylogenetic analysis gave valuable information about the molecular epidemiology of EHV-1 and EHV-4 subtypes prevalent in Egypt.

\section{Declaration of Competing interest}

On behalf of all authors, I hereby declare that no conflict of interest may interfere with the publication of the manuscript.

\section{REFERENCES}

ABDELGAWAD A., DAMIANI A., HO S., STRAUSS G., SZENTIKS C., EAST M. ET AL. 2016. Zebra alphaherpesviruses (EHV-1 and EHV-9): genetic diversity, latency, and coinfections. $\quad$ Viruses $\quad 8,262$. https://doi.org/10.3390/ v8090262

AMER H., SHALTOUT A., EL-SABAGH I., ELSANOUSI A. \&SHALABY M. 2011. Prevalence of equine herpes viruses1, 2 and 4 in Arabian horse population in Egypt.African 
Journal of Microbiology Research 5, 48054811.

BACK H., ULLMAN K., TREIBERG BERNDTSSON L., RIIHIMAKI M., PENELL J., STAHL K. \& PRINGLE J. 2015. Viral load of equine herpesviruses 2 and 5 in nasal swabs of actively racing Standardbred trotters: temporal relationship of shedding to clinical findings and poor performance. Veterinary Microbiology 179, 142-148.

DAVISON AJ, EBERLE R, EHLERS B, HAYWARD GS, MCGEOCH DJ, MINSON AC, PELLETT PE, ROIZMAN B, STUDDERT MJ, THIRY E.2009. The order Herpesvirales. Arch Virol. 2009;154(1):171-7.

HAFSHEJANI, T.T.; NEKOEI, S.; VAZIRIAN, B.; DOOSTI, A.; KHAMESIPOUR, F.; ANYANWU, M.U. 2015. Molecular Detection of Equine Herpesvirus Types 1 and 4 Infection in Healthy Horses in Isfahan Central and Shahrekord Southwest Regions, Iran. Biomed Res Int. 2015;2015:917854.

HASSANAIN, M.M., M.H.F. EL-BAGOURY, M.A. KALAD, M.M.A. EL-KABBANY, AND M.A. DAOUD, 2002. Trials for isolation and identification of equine herpesvirus abortion in Egypt. Vet. Med. J. Giza, 50: 977-986.

KAROL STASIAK, MAGDALENA DUNOWSKA, AND JERZY ROLA, 2018. Prevalence and sequence analysis of equid herpesviruses from the respiratory tract of Polish horses. Virology Journal (2018) 15:106

MA G., AZAB W., AND OSTERRIEDER N. 2013. Equine herpesviruses type 1 (EHV-1) and 4 (EHV-4) - masters of co-evolution and a constant threat to equids and beyond," Veterinary Microbiology, vol. 167, no. 1-2, pp. 123-134, 2013.

MARIE GARVEY, RACHEL LYONS, RALPH D HECTOR ORCID, CATHAL WALSH ORCID, SEAN ARKINS, AND ANN CULLINANE. 2019. Molecular Characterisation of Equine Herpesvirus 1 Isolates from Cases of Abortion, Respiratory and Neurological Disease in Ireland between 1990 and 2017. Pathogens, 8(1), 7;

OIE. 2018. OIE MANUAL FOR TERRESTIAL ANIMALS, 2018. Equine rhinopneumonitis, http://www.oie.int/standard-setting/terrestrialmanual /accessonline/2.05.09_EQUINE_RHINO.pdf.

PATEL J R, HELDENS J.2005. Equine herpesviruses 1 (EHV-1) and 4 (EHV-4)-epidemiology, disease, and immunoprophylaxis: a brief review. Vet J. 2005Jul;170(1):14-23

PUSTERLA N., LEUTENEGGER C.M., WILSON W.D., WATSON J.L., FERRARO G.L. \& MADIGAN J.E. (2005) Equine herpesvirus- 4 kinetics in peripheral blood leukocytes and nasopharyngeal secretions in foals using quantitative real-time TaqMan PCR. Journal of Veterinary Diagnostic Investigation 17, 578581 .
SARANI A., MOHAMMADI G., MAYAMEEI A., AND AKBARI M.2013. Investigation of equine herpesvirus-1 and four infections in equine population of Iran by real-time PCR, Human \& VeterinaryMedicine-Bioflux, vol. 5, no. 1, pp. 29-33,

SCHROEDER, M.E.; BOUNPHENG, M.A. ; RODGERS, S. ; BAKER, R.J.; BLACK, W.; NAIKARE, H.; VELAYUDHAN, B.; SNEED, L.; SZONYI, B. AND CLAVIJO, A. 2012. Development and performance evaluation of calf diarrhea pathogen nucleic acid purification and detection workflow. $\mathrm{J} \quad \mathrm{Vet}$ Diagn Invest. 2012 Sep;24 (5):945-53.

STASIAK K, DUNOWSKA M, ROLA J.2018. Prevalence and sequence analysis of equid herpesviruses from the respiratory tract of Polish horses.Virol J. 2018 Jul 11;15(1):106.

TAGHI TAKTAZ HAFSHEJANI, SHAHIN NEKOEI, BEHNAM VAZIRIAN, ABBAS DOOSTI, FAHAM KHAMESIPOUR, AND MADUBUIKE UMUNNA ANYANWU.2015. Molecular Detection of Equine Herpesvirus Types 1 and 4Infection in Healthy Horses in Isfahan Central and Shahrekord Southwest Regions, Iran Hindawi Publishing Corporation BioMed Research International Volume 2015, Article ID 917854, 7 pages http://dx.doi.org/10.1155/2015/917854

WALID AZAB, SAMEH BEDAIR, AZZA ABDELGAWAD, KATHRIN ESCHKE, GEMELAT K. FARAG, ALI ABDELRAHEIM§, ALEX D. GREENWOOD, NIKOLAUS OSTERRIEDER AND AHMED A. H. ALI, 2019. Detection of equid herpesviruses among different Arabian horse populations in Egypt Veterinary Medicine and Science (2019), 5, pp. 361-371

WARDA, S.A., N.K. MADKOUR, N.S. SALEH, S. KASEM, AND M.A. KALAD,2013. Isolation $\&$ identification of EHV-I from an aborted mare at early pregnancy. Bs. Vet. Med. J., 22: 41-45.

How to cite this article:

Morcos Ibrahim Yanni; Ebtsam, A. Abouelyazeed; Hala Abdelrehim Ali and Nadia Maher Hanna, 2021. Verification Of Molecular And Conventional Techniques Used In The Diagnosis Of Equine Herpes Virus In Some Egyptian Governorates. Journal of Applied Veterinary Sciences, 6(1): $1-8$.

DOI: $\underline{\text { https://dx.doi.org/10.21608/javs.2021.140052 }}$ 